\title{
Traditional Medicine to Modern Pharmacogenomics: Ayurveda Prakriti Type and CYP2C19 Gene Polymorphism Associated with the Metabolic Variability
}

\author{
Yogita Ghodke, ${ }^{1}$ Kalpana Joshi, ${ }^{2}$ and Bhushan Patwardhan ${ }^{1}$ \\ ${ }^{1}$ Bioprospecting Laboratory, Interdisciplinary School of Health Sciences, University of Pune, India \\ ${ }^{2}$ Department of Biotechnology, Sinhagad College of Engineering, Pune 411041, India
}

Correspondence should be addressed to Kalpana Joshi, kalpana@unipune.ernet.in

Received 17 November 2008; Accepted 10 November 2009

Copyright (C) 2011 Yogita Ghodke et al. This is an open access article distributed under the Creative Commons Attribution License, which permits unrestricted use, distribution, and reproduction in any medium, provided the original work is properly cited.

Traditional Indian medicine-Ayurveda-classifies the human population into three major constituents or Prakriti known as Vata, Pitta and Kapha types. Earlier, we have demonstrated a proof of concept to support genetic basis for Prakriti. The descriptions in Ayurveda indicate that individuals with Pitta Prakriti are fast metabolizers while those of Kapha Prakriti are slow metabolizers. We hypothesized that different Prakriti may have different drug metabolism rates associated with drug metabolizing enzyme (DME) polymorphism. We did CYP2C19 (Phase I DME) genotyping in 132 unrelated healthy subjects of either sex by polymerase chain reaction-restriction fragment length polymorphism (PCR-RFLP) technique. We observed significant association between CYP2C19 genotype and major classes of Prakriti types. The extensive metabolizer (EM) genotype $\left({ }^{*} 1 /{ }^{*} 1,{ }^{*} 1 /{ }^{*} 2,{ }^{*} 1 /{ }^{*} 3\right)$ was found to be predominant in Pitta Prakriti (91\%). Genotype $\left({ }^{*} 1 / * 3\right)$ specific for EM group was present only in Pitta Prakriti. Poor metabolizer (PM) genotype $\left({ }^{*} 2 / 22,{ }^{*} /{ }^{*} 3, * 3 /{ }^{*} 3\right)$ was highest $(31 \%)$ in Kapha Prakriti when compared with Vata (12\%) and Pitta Prakriti (9\%). Genotype $\left({ }^{*} 2 /{ }^{*} 3\right.$ ) which is typical for PM group was significant in Kapha Prakriti (odds ratio $=3.5, P=.008$ ). We observed interesting correlations between CYP2C19 genotypes and Prakriti with fast and slow metabolism being one of the major distinguishing and differentiating characteristics. These observations are likely to have significant impact on phenotype-genotype correlation, drug discovery, pharmacogenomics and personalized medicine.

\section{Introduction}

Ayurveda remains one of the most ancient and yet living traditions documented and practiced widely in India [1]. It has a time-honored philosophical and experiential basis. The core concept of health and disease in Ayurveda is built around the uniqueness of an individual [2]. Ayurveda uses a 3-fold classification known as tridosha theory that identifies principles of motion (Vata), metabolism (Pitta) and structure (Kapha) as discrete phenotypic groupings [3]. According to Ayurveda, the individual constitution or Prakriti classification is based on differences in physical, physiological and psychological characteristics and is independent of racial, ethnic or geographical considerations. The importance of such individual variations in health and disease is an important basic principle rightly described hundreds of years ago as "every individual is different from another and hence should be considered as a different entity; as many variations are there in the Universe, all are seen in the human being" [4-6]. The doshas exhibit more easily recognizable phenotypes. Evidence-based research in Ayurveda is receiving larger acceptance in India and abroad [7-9].

According to Ayurveda, Prakriti of an individual is determined at the time of conception and remains unaltered during the lifetime. Prakriti-specific treatment including medicine, diet and lifestyle is a distinctive feature of Ayurveda [10]. We hypothesized that Prakriti has a genetic connotation that can provide a tool for classifying human population based on broad phenotype clusters. We hypothesize that the human phenome based on Ayurveda can provide a genetic basis for the three major constitutions or Prakriti. Earlier, in a pilot study, we evaluated 76 subjects both for their Prakriti and HLA DRB1 typing. We observed a significant correlation between certain HLA types and Prakriti types [11]. For better validation, the homologous 
relation of Vata (V), Pitta (P) and Kapha (K) to human genetic structure requires further study [12].

Three major constitution types as Vata, Pitta and Kapha Prakriti have unique putative metabolic activities. Kapha is slow, Pitta is fast, while Vata is considered to have variable metabolism. We hypothesize that this may relate to drug metabolism and genetic polymorphism of drug metabolizing enzymes (DME). Inter-individual variability in drug response can be attributed to polymorphism in genes encoding different DMEs, drug transporters and enzymes involved in DNA biosynthesis and repair [13, 14]. Mutation in gene coding for DMEs may result in variants with high, low or no activity. Major genetic polymorphisms affecting DME activity are related to drug oxidation by cytochrome P450 enzymes (CYP) 2C19, 2C9 and 2D6 [15, 16]. Such polymorphism gives rise to important inter-individual and inter-ethnic variability in the metabolism and disposition of several therapeutic agents resulting in differences in clinical response to these drugs.

The CYP2C19 gene is one of the members of cytochrome P-450 (CYP) super family enzymes involved in metabolism of a number of drugs $[15,17]$ and accounts for about $2 \%$ of oxidative drug metabolism in humans [18]. In the context of this paper, it is important to understand how genetic factors influence CYP2C19 levels and activities. Among the 25 variants of CYP2C19, two principle alleles CYP2C19*2 and $\mathrm{CYP}_{2} \mathrm{C1}^{*} 3$ have been reported with Poor Metabolizer (PM) phenotype in Caucasians and Asian populations [19, 20]. The presence of the CYP2C19*2 alleles leads to an aberrant splice site, whereas the CYP2C19*3 allele produces a premature stop codon [21]. The importance of this polymorphism has recently been shown as differences in omeprazole concentrations and gastric acid suppression in poor and extensive metabolizers (EMs) of CYP2C19 [22]. Individuals with homozygous $\left({ }^{*} 1 /{ }^{*} 1\right)$ or heterozygous $(* 1 / * 2$, ${ }^{*} 1 /{ }^{*} 3$ ) wild-type CYP2C19*1 genotype have efficient enzyme to metabolize CYP2C19 substrates and are EMs. Individuals with homozygous $(* 2 / 2, * 3 / * 3)$ or heterozygous mutant CYP2C19*2/CYP2C19*3 genotype have reduced enzyme activity and are termed as PMs.

We chose the CYP2C19 gene polymorphism to study inter-individual variability in drug metabolism and its possible association with metabolically polymorphic Prakriti. We investigated the distribution of CYP2C19 genotypes in 132 healthy individuals with different Prakriti classes using PCRRFLP technique. Our study observes an association between CYP2C19 genotype and Ayurveda-based constitution or Prakriti.

\section{Methods}

2.1. Prakriti Evaluation. The Prakriti of each subject was assessed using a validated questionnaire based on physical, physiological and psychological characteristics, and clinical judgment of senior Ayurvedic experts. Physique, skin texture, hunger, thirst, digestive capacity, temperament and memory are some of the attributes evaluated to determine individual constitution. The questionnaire also considered information regarding ethnicity, maternal and paternal family history of diseases, past history related to diseases, allergies and dietary habits. Predominant Prakriti was allotted if $\geq 70 \%$ dominance of a single Dosha score was obtained. Only individuals with predominance of either of $\mathrm{V}, \mathrm{P}$ or $\mathrm{K}$ were included in the study. Each subject was also assessed clinically by an Ayurvedic expert physician or Vaidya who independently classified all subjects into $\mathrm{V}, \mathrm{P}$ or $\mathrm{K}$ groups. Finally, subjects were recruited in this study only when $80 \%$ concordance was observed between Prakriti assessment with questionnaire scores and clinical evaluation by Vaidya. The borderline cases were referred to additional senior Vaidya whose decision was considered final.

2.2. Subject Screening and Study Population. The study was conducted among the Maharashtrian population residing in Western India and belonging to Australoid-Europoid origin [23]. This avoided any confounding factors due to population stratification. Total 489 subjects were screened and 167 subjects having predominant Prakriti types were identified. Subsequently, from these 167 subjects a total of 132 unrelated ethnically matched healthy subjects of both sexes (62 males and 70 females) with predominance of either V (26 subjects), P (43) or K (63) were recruited for the genotyping study, with a mean age of 23.22 (SD 5.3) years. The study protocol was approved by the Ethics Committee of Interdisciplinary School of Health Sciences, University of Pune, India, and written informed consent was obtained from all subjects.

2.3. Genotyping for CYP2C19. About $5 \mathrm{~mL}$ of venous blood was drawn from each subject in a vacutainer containing EDTA as an anticoagulant. DNA was extracted using Miller's protocol [24]. Genotyping of extracted DNA for CYP2C19*1, CYP2C19*2 and CYP2C19*3 alleles was done using the PCRRFLP technique as reported earlier [25]. Samples containing mutants were reanalyzed to ensure that the method was $100 \%$ reproducible and accurate.

2.4. Statistical Analysis. Statistical analysis was performed using the Graph Pad Prism statistical software (San Diego, CA, USA). Using available CYP2C19 genotype data, genotype frequencies were calculated and $2 \times 2$ contingency tables were constructed using one Prakriti group against the remaining two groups. Data related to CYP2C19 genotype and three Prakriti types was analyzed using Fisher's exact probability test as the number of individuals in some of the Prakriti classes having a particular genotype was very small.

\section{Results}

3.1. Prakriti Distribution. A total of 132 subjects were classified in three major categories of Prakriti: 63 (47.7\%) of $\mathrm{K}, 43(32.6 \%)$ of $\mathrm{P}$ and 26 (19.7\%) of $\mathrm{V}$.

3.2. CYP2C19 Genotype Distribution in Prakriti Classes. The genotype frequencies of CYP2C19 polymorphisms in V, $\mathrm{P}$ and $\mathrm{K}$ Prakriti are presented in Table 1 . The genotypic 

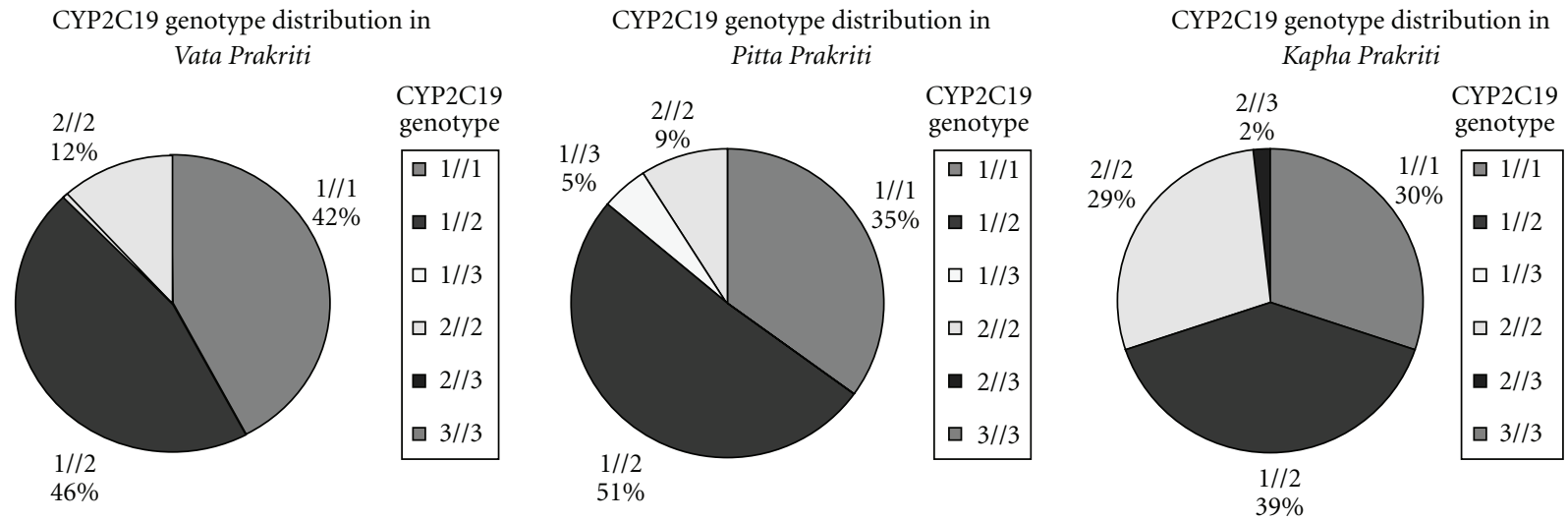

FIgURe 1

TABLE 1: Genotype frequencies of CYP2C19 gene polymorphism in V, P and K Prakriti.

\begin{tabular}{|c|c|c|c|c|c|c|c|c|c|}
\hline \multirow{2}{*}{ CYP2C19 Genotype } & \multicolumn{2}{|c|}{ Phenotype frequency } & \multirow{2}{*}{$P$} & \multicolumn{2}{|c|}{ Phenotype frequency } & \multirow{2}{*}{$P$} & \multicolumn{2}{|c|}{ Phenotype frequency } & \multirow{2}{*}{$P$} \\
\hline & $\begin{array}{l}\text { Vata } \\
n=26(\%)\end{array}$ & $\begin{array}{c}\text { Kapha + Pitta } \\
n=106(\%)\end{array}$ & & $\begin{array}{l}\text { Pitta } \\
n=43(\%)\end{array}$ & $\begin{array}{c}\text { Kapha + Vata } \\
n=89(\%)\end{array}$ & & $\begin{array}{l}\text { Kapha } \\
n=63(\%)\end{array}$ & $\begin{array}{c}\text { Pitta + Vata } \\
n=69(\%)\end{array}$ & \\
\hline $1 / 1$ & $11(42.31)$ & $34(32.08)$ & .360 & $15(34.88)$ & $30(33.70)$ & 1.000 & $19(30.16)$ & $26(37.68)$ & .462 \\
\hline $1 / 2$ & $12(46.15)$ & $47(44.34)$ & 1.000 & $22(51.16)$ & $37(41.57)$ & .351 & $25(39.68)$ & $34(49.27)$ & .296 \\
\hline $1 / 3$ & - & $2(1.89)$ & 1.000 & $2(4.65)$ & - & .104 & - & $2(2.89)$ & .497 \\
\hline $2 / 2$ & $3(11.54)$ & $22(20.75)$ & .404 & $4(9.32)$ & $21(23.59)$ & .059 & $18(28.57)$ & $7(10.14)$ & .008 \\
\hline $2 / 3$ & - & $1(0.94)$ & 1.000 & - & $1(1.12)$ & 1.000 & $1(1.59)$ & - & .477 \\
\hline $3 / 3$ & - & - & 一 & - & - & 一 & - & - & 一 \\
\hline
\end{tabular}

repertoire in this population represents predominance of CYP $2 C 19 * 1 / * 2$ genotype as compared to other genotypes. This genotype was well distributed in all the three dominant Prakriti types. EM genotype $\left(*^{*} 1 /{ }^{*} 1,{ }^{*} 1 /{ }^{*} 2, *^{*} 1 / * 3\right)$ was found to be predominant in $\mathrm{P}(91 \%)$. The ${ }^{*} 1 / * 3$ genotype specific for the EM group was present only in P. The PM genotype $\left(*_{2} /{ }^{*} 2, *^{*} /{ }^{*} 3, *_{3} /{ }^{*} 3\right)$ was highest $(31 \%)$ in $\mathrm{K}$ when compared with $\mathrm{V}(12 \%)$ and $\mathrm{P}(9 \%)$. CYP2C19 *2/*2 genotype frequency was significantly higher with $P$ value $=.008$ in $\mathrm{K}$ type as compared to $\mathrm{V}+\mathrm{P}$ types yielding an Odds Ratio of 3.5. The $* 2 / * 3$ genotype typical for PM group was observed only in K Prakriti. V Prakriti did not show any significant association with any of the genotypes. Although our results did not reach statistical significance, a positive trend was evident in Prakriti CYP2C19 genotype association.

\section{Discussion}

Earlier, in an exploratory study correlating HLA DRB1 alleles with ayurvedic Prakriti classification, we suggested a genetic basis for the system classification [26]. Present study gives preliminary evidence for the metabolic variability of different Prakriti types using DME CYP2C19 gene polymorphism model.

The results obtained in this study suggest possible association of CYP2C19 gene polymorphism with Prakriti phenotypes. We observed predominance of EM genotypes $\left({ }^{*} 1 /{ }^{*} 1,{ }^{*} 1 /{ }^{*} 2, * 1 / * 3\right)$ in P Prakriti with fast metabolism. The $\mathrm{PM}$ genotypes $\left(*^{*} /{ }^{*} 2, *^{*} /{ }^{*} 3, *^{*} /{ }^{*} 3\right)$ were highest in $\mathrm{K}$ that is expected to be metabolically slow. The CYP2C19 *2/*2 genotype frequency was significantly higher in $\mathrm{K}$ type as compared to $\mathrm{V}+\mathrm{P}$ types. The reported frequencies of $* 1 /{ }^{*} 3$ and $*^{*} / *^{*}$ genotypes in Maharashtrian population is very low- $-1.4 \%$ and $0.7 \%$, respectively [25]. It is interesting to note that ${ }^{*} 1 /{ }^{*} 3$ genotype specific for the EM group was present only in $\mathrm{P}$ and $* 2 / * 3$ genotype typical for $\mathrm{PM}$ group was observed in $\mathrm{K}$, as expected. The $\mathrm{V}$ type did not show any significant association with any of the genotypes. Some of the genotypes were common to two or more Prakriti classes confirming the overlap of doshas among Prakriti classes (Figure 1). These results allow us to predict that $\mathrm{K}$ and $\mathrm{P}$ being slow and fast metabolizer groups are likely to require low and high doses of CYP2C19 substrates such as diazepam, certain barbiturates, tricyclic antidepressants, omeprazole and proguanil.

This exploratory study was aimed at investigating metabolic variability in Prakriti classes and its relation with the gene polymorphism. One of the limitations of our study is the small sample size and hence, positive associations need to be confirmed with large sample size. Extensive studies on Prakriti subtypes and genome wide single nucleotide polymorphism (SNP) mapping especially of other important DME polymorphisms like CYP2D6, CYP2C9, CYP3A4, TPMT, and so forth, would be useful to understand possible Prakriti pharmacogenomics relationship correlating genotype, Prakriti and drug metabolism. The data generated in this study could be further supported by pharmacokinetic studies on $\mathrm{K}$ and $\mathrm{P}$ subjects. We have initiated studies 
on the effect of Prakriti and gene polymorphism on drug metabolism and clinical outcome in rheumatoid arthritis patients.

Few earlier studies have attempted to address the relationship between traditional medicine constitutions and HLA polymorphism [27-29]. Studies on whole genome expression [30] and the pharmacogenomics of medicinal plants $[31,32]$ have also been attempted. There are several similarities between Ayurveda and the Traditional Chinese Medicine (TCM), including the holistic and individual classification systems [33]. Genomics/proteomics correlates of Sasang constitutional medicine (SCM) and Kampo medicine have been reported recently [34-38]. Advancements in the analytical and biological sciences, along with innovations in genomics and proteomics can play an important role in validation of these ancient therapies [39]. Our study demonstrates a probable genomic basis for metabolic differences attributed by Prakriti. Identification of genetic variations underlying metabolic variability in Prakriti may provide newer approach to Pharmacogenomics.

\section{Acknowledgments}

Y.G. thanks the Council for Scientific and Industrial Research, New Delhi, India, for senior research fellowship. The authors thank Dr Girish Tillu and Dr Ganesh for their help in subject recruitment and blood collection, and Ms Pooja Shintre, Ms Aditi Chiplunkar and Mr Yashendra Aarya for technical assistance. The assistance given by staff at Tilak Ayurveda College during subject recruitment and blood collection is gratefully acknowledged.

\section{References}

[1] C. Dwarakanath, The Fundamental Principles of Ayurveda, Krishnadas Academy, Varanasi, India, 1952.

[2] B. Patwardhan, A. D. B. Vaidya, and M. Chorghade, "Ayurveda and natural products drug discovery," Current Science, vol. 86, no. 6, pp. 789-799, 2004.

[3] A. Hankey, "A test of the systems analysis underlying the scientific theory of Ayurveda's tridosha," Journal of Alternative and Complementary Medicine, vol. 11, no. 3, pp. 385-390, 2005.

[4] K. Shastri, Charaka Samhita, Chaukhambha Sanskrit Sansthan, Varanasi, India, 6th edition, 1995.

[5] M. S. Valiathan, The Legacy of Caraka, Orient Longman, Chennai, India, 2003.

[6] H. Sharma and C. Clark, Contemporary Ayurveda, Churchill Livingstone, Philadelphia, Pa, USA, 1997.

[7] R. A. Mashelkar, "Second world ayurveda congress (Theme: Ayurveda for the Future)-inaugural address: part III," Evidence-Based Complementary and Alternative Medicine, vol. 5, pp. 367-369, 2008.

[8] E. L. Cooper, "Ayurveda is embraced by eCAM," EvidenceBased Complementary and Alternative Medicine, vol. 5, no. 1, pp. 1-2, 2008.

[9] E. L. Cooper, "Ayurveda and eCAM: a closer connection," Evidence-Based Complementary and Alternative Medicine, vol. 5, no. 2, pp. 121-122, 2008.
[10] R. E. Swoboda, Prakriti: Your Ayurvedic Constitution, Motilal Banarasidass Publishers, New Delhi, India, 1996.

[11] P. Bhushan, J. Kalpana, and C. Arvind, "Classification of human population based on HLA gene polymorphism and the concept of Prakriti in Ayurveda," Journal of Alternative and Complementary Medicine, vol. 11, no. 2, pp. 349-353, 2005.

[12] B. Patwardhan and G. Bodeker, "Ayurvedic genomics: establishing a genetic basis for mind-body typologies," Journal of Alternative and Complementary Medicine, vol. 14, no. 5, pp. 571-576, 2008.

[13] W. E. Evans, "Pharmacogenomics: marshalling the human genome to individualise drug therapy," Gut, vol. 52, supplement 2, pp. ii10-ii18, 2003.

[14] W. E. Evans and H. L. McLeod, "Pharmacogenomics-drug disposition, drug targets, and side effects," The New England Journal of Medicine, vol. 348, no. 6, pp. 538-549, 2003.

[15] J. A. Goldstein and S. M. F. de Morais, "Biochemistry and molecular biology of the human CYP2C subfamily," Pharmacogenetics, vol. 4, no. 6, pp. 285-299, 1994.

[16] L. Bertilsson, M.-L. Dahl, P. Dalén, and A. Al-Shurbaji, "Molecular genetics of CYP2D6: clinical relevance with focus on psychotropic drugs," British Journal of Clinical Pharmacology, vol. 53, no. 2, pp. 111-122, 2002.

[17] A. K. Daly, "Molecular basis of polymorphic drug metabolism," Journal of Molecular Medicine, vol. 73, no. 11, pp. 539-553, 1995.

[18] F. P. Guengerich, "In vitro techniques for studying drug metabolism," Journal of Pharmacokinetics and Biopharmaceutics, vol. 24, no. 5, pp. 521-533, 1996.

[19] S. M. F. de Morais, G. R. Wilkinson, J. Blaisdell, K. Nakamura, U. A. Meyer, and J. A. Goldstein, "The major genetic defect responsible for the polymorphism of S- mephenytoin metabolism in humans," The Journal of Biological Chemistry, vol. 269, no. 22, pp. 15419-15422, 1994.

[20] S. M. F. de Morais, G. R. Wilkinson, J. Blaisdell, U. A. Meyer, K. Nakamura, and J. A. Goldstein, "Identification of a new genetic defect responsible for the polymorphism of (S)mephenytoin metabolism in Japanese," Molecular Pharmacology, vol. 46, no. 4, pp. 594-598, 1994.

[21] J. A. Goldstein and J. Blaisdell, "Genetic tests which identify the principle defects in CYP2C19 responsible for the polymorphism in Mephenytoin metabolism," Methods in Enzymology, vol. 272, pp. 210-217, 1996.

[22] M. Chang, G. Tybring, M. L. Dahl et al., "Interphenotypic differences in disposition and effect on gastric levels of Omeprazole as a probe for CYP2C19," British Journal of Clinical Pharmacology, vol. 39, pp. 511-518, 1995.

[23] I. Karve, Maharashtra-Land \& Its People, Maharashtra State Gazetteers General Series. Bombay Directorate of Government Printing, Stationary \& Publications, Norwich, UK, 1968.

[24] S. A. Miller, D. D. Dykes, and H. F. Polesky, "A simple salting out procedure for extracting DNA from human nucleated cells," Nucleic Acids Research, vol. 16, no. 3, p. 1215, 1988.

[25] Y. Ghodke, K. Joshi, Y. Arya et al., "Genetic polymorphism of CYP2C19 in Maharashtrian population," European Journal of Epidemiology, vol. 22, no. 12, pp. 907-915, 2007.

[26] B. Patwardhan, K. Joshi, and Y. Ghodke, "Genetic basis to concept of prakriti," Current Science, vol. 90, no. 7, p. 896, 2006.

[27] G. X. Zhou, J. Lin, and S. Z. Zhang, "Correlation between constitution type in traditional Chinese medicine of healthy subjects and frequency distribution of HLA gene of the Han 
tribe in Guangdong," Zhongguo Zhongxiyi Jiehe Zazhi, vol. 7, pp. 519-522, 1987.

[28] L. Chen and J. Chen, "The correlative research advances of human leukocyte antigen and theory of TCM," Chinese Archives of Traditional Chinese Medicine, vol. 22, pp. 12841285, 2004.

[29] S. Chen, F. Lv, J. Gao et al., "HLA class II polymorphisms associated with the physiologic characteristics defined by traditional Chinese medicine: linking modern genetics with an ancient medicine," Journal of Alternative and Complementary Medicine, vol. 13, pp. 231-239, 2007.

[30] B. Prasher, S. Aggarwal, A. K. Mandal et al., "Whole genome expression and biochemical correlates of extreme constitutional types defined in Ayurveda," Journal of Translational Medicine, vol. 6, article no. 48, 2008.

[31] P. Chavan, K. Joshi, and B. Patwardhan, "DNA microarrays in herbal drug research," Evidence-Based Complementary and Alternative Medicine, vol. 3, no. 4, pp. 447-457, 2006.

[32] C. C. Deocaris, N. Widodo, R. Wadhwa, and S. C. Kaul, "Merger of Ayurveda and tissue culture-based functional genomics: inspirations from systems biology," Journal of Translational Medicine, vol. 6, article 14, 2008.

[33] B. Patwardhan, D. Warude, P. Pushpangadan, and N. Bhatt, "Ayurveda and traditional Chinese medicine: a comparative overview," Evidence-Based Complementary and Alternative Medicine, vol. 2, no. 4, pp. 465-473, 2005.

[34] D. Noble, "Could there be a synthesis between western and Oriental medicine, and with Sasang constitutional medicine in particular?" Evidence-Based Complementary and Alternative Medicine, vol. 6, supplement 1, pp. 5-10.

[35] J. Kim and D. Pham, "Sasang constitutional medicine as a holistic tailored medicine," Evidence-Based Complementary and Alternative Medicine, vol. 6, pp. 11-19, 2009.

[36] B.-Y. Kim, S. Cha, H.-J. Jin, and S. Jeong, "Genetic approach to elucidation of sasang constitutional medicine," Evidence-Based Complementary and Alternative Medicine, vol. 6, no. 1, pp. 5157, 2009.

[37] H.-H. Won, S. Lee, E. Jang et al., "A genome-wide scan for the sasang constitution in a korean family suggests significant linkage at chromosomes 8q11.22-23 and 11q22.1-3," Journal of Alternative and Complementary Medicine, vol. 15, no. 7, pp. 765-769, 2009.

[38] C. Matsumoto, T. Kojima, K. Ogawa et al., "A proteomic approach for the diagnosis of 'Oketsu' (blood stasis), a pathophysiologic concept of Japanese traditional (Kampo) medicine," Evidence-Based Complementary and Alternative Medicine, vol. 5, no. 4, pp. 463-474, 2008.

[39] E. L. Cooper, "ECAM: integrative genomics and fecundity," Evidence-Based Complementary and Alternative Medicine, vol. 6, no. 2, pp. 129-131, 2009. 


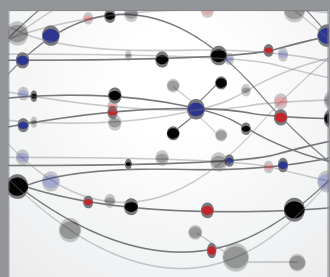

The Scientific World Journal
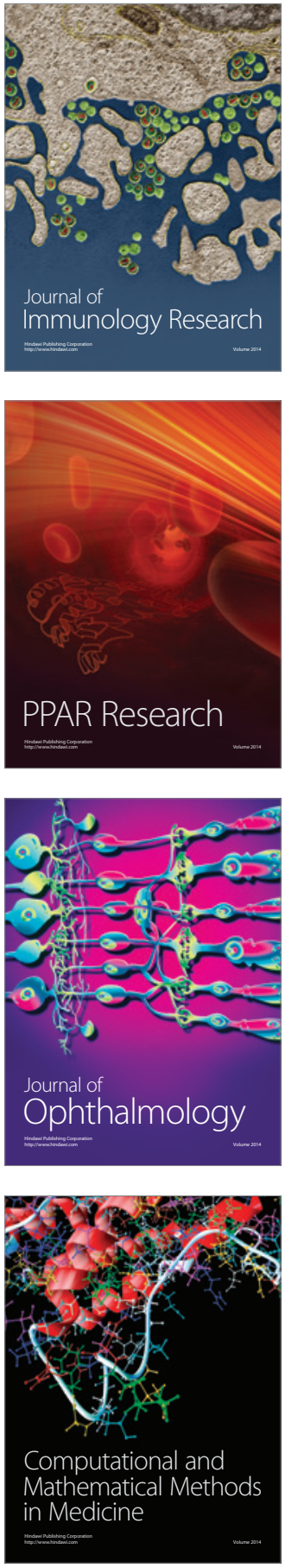

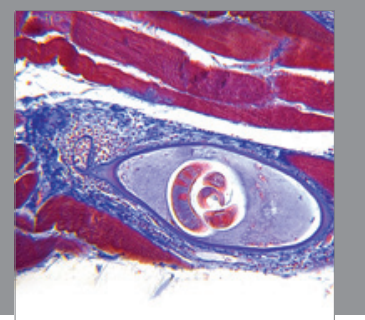

Gastroenterology

Research and Practice
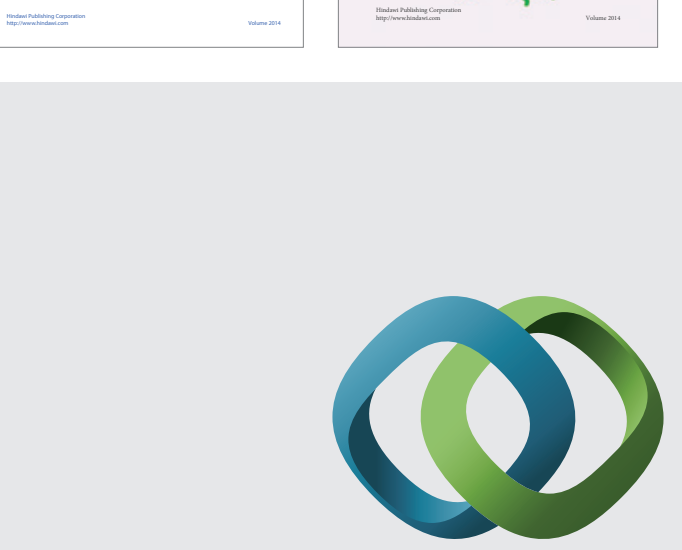

\section{Hindawi}

Submit your manuscripts at

http://www.hindawi.com
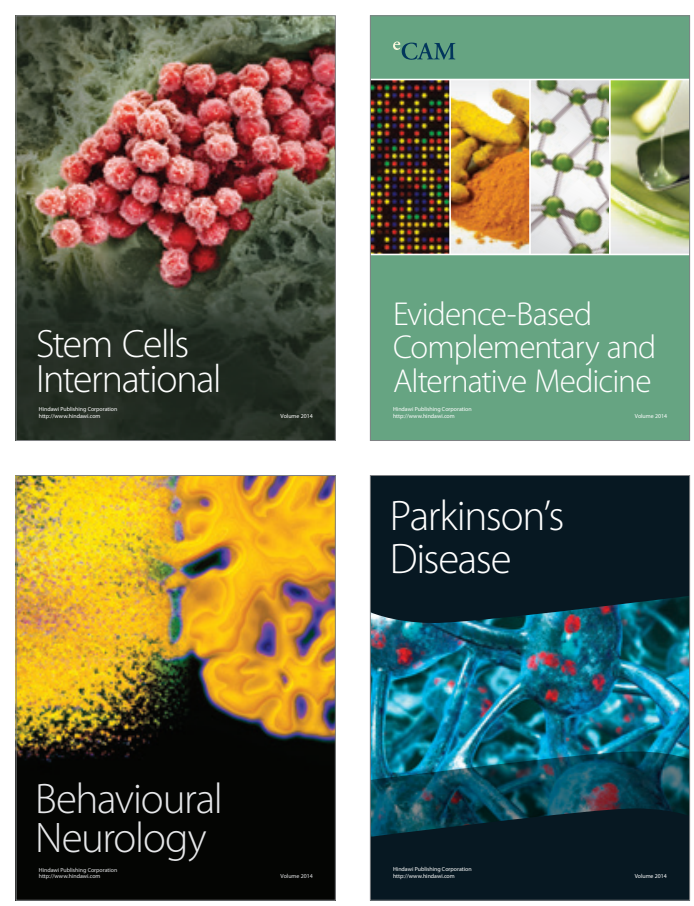

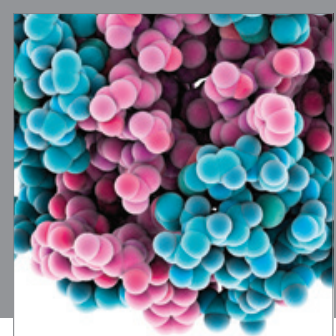

Journal of
Diabetes Research

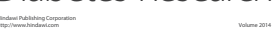

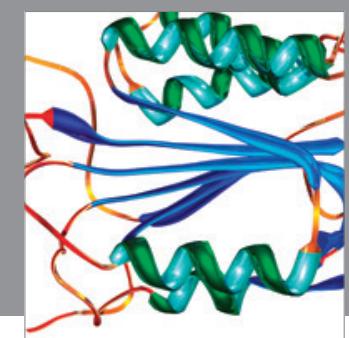

Disease Markers
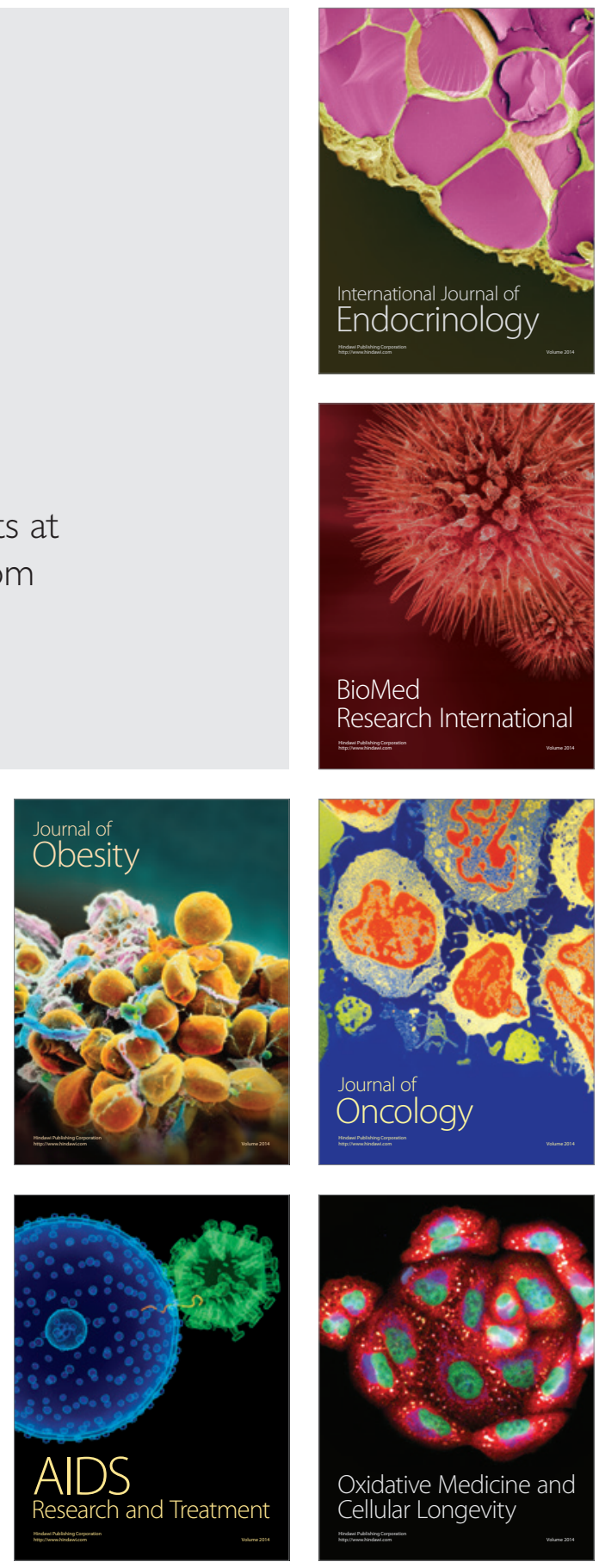